\title{
A review of physical supply and EROI of fossil fuels in China
}

\author{
Jian-Liang Wang ${ }^{1} \cdot J^{\prime a n g-X u a n ~ F e n g ~}{ }^{1} \cdot$ Yongmei Bentley $^{2} \cdot$ Lian-Yong Feng $^{1} \cdot$ \\ Hui $\mathbf{Q u}^{3}$
}

\begin{abstract}
This paper reviews China's future fossil fuel supply from the perspectives of physical output and net energy output. Comprehensive analyses of physical output of fossil fuels suggest that China's total oil production will likely reach its peak, at about $230 \mathrm{Mt} /$ year (or $9.6 \mathrm{EJ} / \mathrm{year}$ ), in 2018; its total gas production will peak at around $350 \mathrm{Bcm} /$ year (or $13.6 \mathrm{EJ} / \mathrm{year}$ ) in 2040, while coal production will peak at about $4400 \mathrm{Mt} /$ year (or $91.9 \mathrm{EJ} / \mathrm{year}$ ) around 2020 or so. In terms of the forecast production of these fuels, there are significant differences among current studies. These differences can be mainly explained by different ultimately recoverable resources assumptions, the nature of the models used, and differences in the historical production data. Due to the future constraints on fossil fuels production, a large gap is projected to grow between domestic supply and demand, which will need to be met by increasing imports. Net energy analyses show that both coal and oil and gas production show a steady declining trend of EROI (energy return on investment) due to the depletion of shallow-buried coal resources and conventional oil and gas resources, which is generally consistent with the approaching peaks of physical production of fossil
\end{abstract}

Jian-Liang Wang

wangjianliang305@163.com

1 School of Business Administration, China University of Petroleum, Beijing 102249, China

2 University of Bedfordshire Business School, Luton LU1 3JU, UK

3 Petroleum Industry Press, CNPC, Beijing 100011, China

Edited by Xiu-Qin Zhu. fuels. The peaks of fossil fuels production, coupled with the decline in EROI ratios, are likely to challenge the sustainable development of Chinese society unless new abundant energy resources with high EROI values can be found.

Keywords Peak production - Fossil fuels - Net energy · EROI · China

\section{Introduction}

China has achieved rapid economic growth since beginning its reform and opening up in the 1980s, with an average annual GDP growth rate of $9.8 \%$ from 1978 to 2014 (NBSC 2015). China has now become the second-largest economy in the world after the USA. This great achievement could not have been possible without high energy consumption. From 1978 to 2014, China's total annual energy consumption increased from just over 570 million tonnes of coal equivalent per year (Mtce/year) to $4260 \mathrm{Mtce} /$ year, representing an average annual growth rate of 5.8\% (NBSC 2015). Moreover, most of this energy has been from fossil fuels. In 2014, for example, China's total fossil fuel consumption was 3780 Mtce/year (coal, 2810 Mtce; oil, 730 Mtce; gas, 240 Mtce), accounting for just under $90 \%$ of total energy consumption (the remaining $10 \%$ is renewable energy) (NBSC 2015). A large number of studies have indicated that fossil fuels will continue to dominate China's energy consumption and that demand for these fuels will keep increasing in future, although the rate of this increase may be much lower than in the past, and the structure may also be changed (i.e. stabilizing oil's share, increasing gas's share, and reducing coal's share in primary 
energy use) (Yuan et al. 2016; IEA 2014). It is thus very important for China to understand its supply status in terms of fossil fuel resources.

Guo and $\mathrm{Li}$ (1997) published a peer-reviewed paper which was perhaps the first to discuss the long-term supply status of China's conventional oil resources. Thereafter, a large number of studies quantitatively investigated the future fossil fuel supply situation of China (e.g. Tao and $\mathrm{Li}$ 2007a, b; Feng et al. 2007, 2008a, b). However, the results of these studies differ sharply. For example, while Mohr and Evans (2009) forecast that the peak production of China's coal resources was likely to be at about 2300 million tonnes per year (Mt/year), the forecast by Li (2012) gave this peak in production being reached at over $6000 \mathrm{Mt} /$ year.

Due to such significant differences, policies relying on only one result may have considerable risk. Therefore, it is crucial to present a comprehensive review of such previous studies to provide a full picture of China's future supply of fossil fuels to policy makers. A main aim of this paper is thus to provide a full picture of the supply status of China's fossil fuels by reviewing and analysing currently available literature.

The supply status of fossil fuel resources can be measured from two perspectives: the physical perspective (i.e. physical supply; the volume or weight of physical production of the fuel), and the net energy perspective (i.e. net energy output of the fuel). The reason why we include the net energy perspective in this paper is that for the society, net energy (i.e. subtracting the energy used in production from the energy produced) is the only true energy. However, most current studies have been conducted only from the physical perspective. In 2011, Hu et al. (2011a) were apparently the first to introduce the concepts of net energy and energy return on investment (EROI) into China. Some authors use "energy return on energy invested" (EROEI) for the same concept. Several studies appeared after 2011 which discussed the net energy or EROI for China's fossil fuel resources (e.g. Hu et al. 2011b, 2013a, b, 2014a; Xu et al. 2014). To fully reflect the supply status of fossil fuel resources, the studies from net energy perspective are also reviewed in this paper.

The potential contribution of this paper is to help the policy makers better understand the future long-term supply of China's fossil fuel resources by providing all the possible pathways derived from current available literature, discussing the reasons for their difference, and then presenting recommended results.

\section{Oil production}

China has been a net oil importer since 1993 and a net crude oil importer since 1996 (BP 2015). These events led to concerns being raised about the potential shortage of domestic oil supply, which in turn led to many studies of China's future oil production. This section covers a comprehensive review of the literature on China's conventional oil production, non-conventional oil production, and total oil production, and the implications for China's oil use.

\subsection{Conventional oil production}

\subsubsection{Overall results}

Figure 1 presents the results from various production forecasts of China's conventional oil production, while Table 1 provides additional details of each of these studies. As can be seen in Fig. 1, the different studies present very different results. These studies show a fairly wide range of peak dates for the conventional oil production-from as earlier as 2002 by Yu et al. (2002) to as late as 2037 (Zhang and Jia 2007). The peak production rate forecast could be as low as $140 \mathrm{Mt} /$ year (Tao and Li 2007a) or higher than $236 \mathrm{Mt} /$ year (Zhang and Jia 2007).

\subsubsection{Reasons for difference}

Many reasons could be responsible for these significant differences, but three are believed to be of most important.

The first is that different values of ultimately recoverable resources (URR) were used in the different studies. Table 1 shows that the lowest URR value is 8.2 Gigatonnes (Gt) according to EWG (2007a), while the highest is 24.6 Gt from Wang and Feng (2016). Wang et al. (2015) used the Multi-Cycle Generalized Weng (MCGW) model to forecast that Chinese oil production will peak at 2025, with a peak production of $195 \mathrm{Mt} / \mathrm{year}$. In a separate study, Wang et al. (2016a) used the same MCGW forecast model but obtained different results (with the peak at 2014, and with peak production at $167 \mathrm{Mt} /$ year). The main reason for the difference is that URR was $19.3 \mathrm{Gt}$ in Wang et al. (2015) and lower, at $12.8 \mathrm{Gt}$, in Wang et al. (2016a).

URR, which is a key input factor for most of forecast models listed in Table 1, is usually defined as the total quantities that can be recovered from discovered and undiscovered deposits (Wang and Feng 2016). Based on this definition, URR can be divided into two parts: one is recoverable quantities from discovered deposits (this part includes cumulative production, reserves, and reserve growth); the other is the potential recoverable quantities from undiscovered deposits (USGS 2000). 


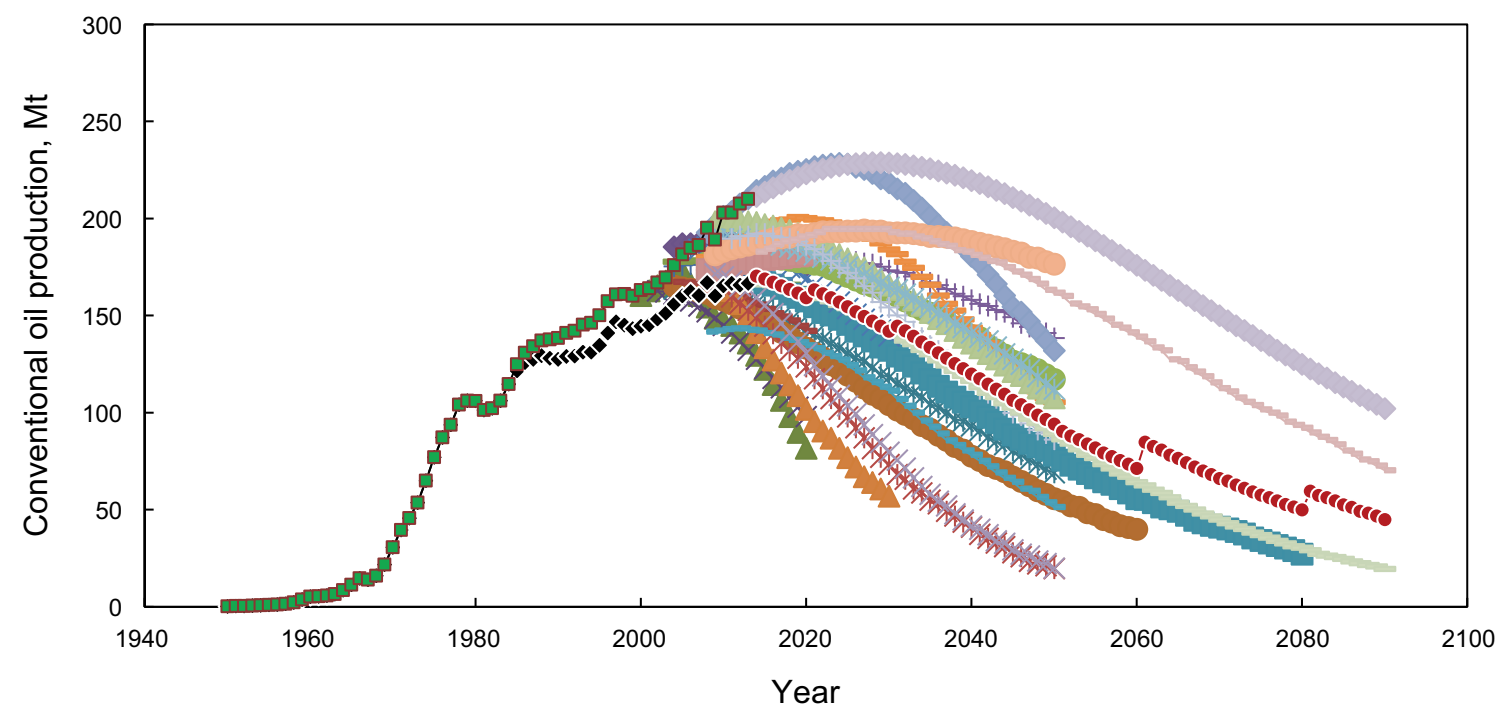

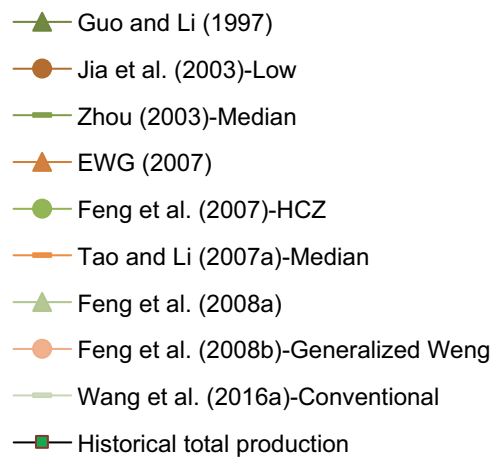

Fig. 1 Production forecasts for China's conventional oil resources. Notes: (1) NGLs have been included; (2) the small vertical steps in the "recommended result" oil production forecast are artefacts of the

One reason of the difference in URR is that non-conventional resources are sometimes also included in statistics of conventional oil resources (Wang et al. 2013a; 2016a). Other reasons are from the assessment process of URR. It is known that the assessment of these recoverable quantities generally needs to consider two factors, i.e. both economic and technical factors (Wang and Feng 2016). The technical factors are usually taken into the resource assessment carried out by Chinese authorities; however, economic factors may be ignored since the primary purpose of resource assessment in China is to know how much resources are there instead of how much resources can be produced by commercial enterprises (Wang et al. 2013a). In this case, assessment results could easily be overestimated if the economic factors are ignored or insufficiently considered. Studies in the literature have shown that the URR values reported by Chinese authorities (URR values higher than $20 \mathrm{Gt}$ in Table 1 are all from various reports by the authorities) probably overestimate the actual URR due to insufficient consideration of economic conditions (Wang et al. 2013a). We should be very careful before using those modelling and are not significant; (3) according to China Energy Statistical Yearbook, $1 \mathrm{~kg}$ oil $=41.78 \mathrm{MJ}$

very high URRs since Hallock et al. (2014) examined the behaviour of petroleum production from some 40 different countries which tended to follow the low URR estimates far more often than medium or high estimates.

The second main reason for the differences in forecasts in Fig. 1 is in the use of different forecast models. Currently, most studies have used different types of curvefitting models, such as Verhulst model, growth curve model, Weng model, HCZ model, Hubbert model, and Richard's model shown in Table 1. According to Wang and Feng (2016), the curve shape of models has considerable impact on forecast results and can be divided into symmetric or asymmetric based on their inflection point. ${ }^{1}$ Asymmetric curves can be further divided into negatively skewed (inflection point $>0.5$ ) and positively skewed

\footnotetext{
${ }^{1}$ The inflection point is where the curvature changes sign, and this point coincides with the maximum production level. The production in symmetric models always peaks when $50 \%$ of the URR has been depleted, i.e., the inflection point of symmetric models $=0.5$. Asymmetric models can have inflection points that occur at an arbitrary depletion level (Wang and Feng 2016).
} 
Table 1 Summary of production forecasts for China's conventional oil resources

\begin{tabular}{|c|c|c|c|c|}
\hline \multirow[t]{2}{*}{ Researchers } & \multirow[t]{2}{*}{ Methodology } & \multirow[t]{2}{*}{ URR, Gt } & \multicolumn{2}{|l|}{ Forecast results } \\
\hline & & & Peak production, Mt/year & Peak year \\
\hline Guo and Li (1997) & GM and Verhulst models & - & 191 & 2005 \\
\hline Shen et al. (2000) & - & 14.0 & 200 & 2020 \\
\hline Wan (2000) & - & - & 180 & 2020 \\
\hline Yu (2002) & Growth curve model & - & 163 & 2002 \\
\hline Chen (2003) & HCZ model & 12.0 & 164 & 2005 \\
\hline Jia et al. (2003) & - & $11-14$ & 180 & 2010 \\
\hline Zhou (2003) & Weng model & $11-14$ & $167-187$ & 2004-2010 \\
\hline Mou (2004) & - & - & $180-200$ & 2020 \\
\hline Pang et al. (2005) & - & - & 175 & 2010 \\
\hline Yang et al. (2006) & - & - & 180 & 2007 \\
\hline Zhang and Jia (2007) & Analogy forecast model & - & $190-236$ & $2015-2037$ \\
\hline EWG (2007a) & Logistic model & 8.2 & 187 & 2006 \\
\hline Feng et al. (2007) & Hubbert, HCZ and Gen. Weng models & & $172-185$ & $2005-2017$ \\
\hline Tao and Li (2007a) & SD model & $10-16$ & $143-228$ & $2010-2022$ \\
\hline Feng et al. (2008a) & HCZ model & 15.6 & 198 & 2011 \\
\hline Feng et al. (2008b) & Hubbert, HCZ and Gen. Weng models & - & $172-194$ & $2005-2026$ \\
\hline Pang et al. (2009) & - & - & 200 & 2026 \\
\hline Tang et al. (2010) & SD model & 13.4 & 193 & 2015 \\
\hline Wang et al. (2015) & MCGW model & 19.3 & 195 & 2025 \\
\hline Wang et al. (2016a) & MCGW model & 12.8 & 167 & 2014 \\
\hline Wang and Feng (2016) & Multi-Richard's model & 24.6 & 229 & 2028 \\
\hline Summary & & $8.2-24.6$ & $143-229$ & $2002-2037$ \\
\hline Recommended result in & aper* & About 14 & About 170 & About 2014 \\
\hline
\end{tabular}

The symbol "-"means that data are not available, or only qualitative analysis

GM Grey model, EWG Energy watch group, Gen. Weng model Generalized Weng model, HCZ model Hu, Chen and Zhang model, SD model System Dynamic model, MCGW model Multi-cycle generalized Weng model

* This represents the average value of the collected data except the value in Wang and Feng (2016) and is also our "recommended result" in Fig. 1, based on our analysis, see discussion in the text

shapes (inflection point $<0.5$ ). Generally, the models with a positively skewed curve shape result in lower peak production and lower post-peak decline rate, while models with a negatively skewed curve result in higher peak production and higher post-peak decline rate (Wang and Feng 2016). Brandt (2007) investigated 67 post-peak regions and found that the actual production curves in most regions show a positive skew. Wang et al. (2011) also pointed out the positively skewed curve is better than the symmetric curve for production forecasting. Therefore, it is reasonable to exclude the results estimated by the models with a negatively skewed curve. Luckily, there are no negatively skewed curve-fitting models in Table 1. However, other curve-fitting models with different inflection points may also affect the forecast results. More detailed discussion of the impacts of curve-fitting models on forecast results can be found in Wang and Feng (2016).
The third main reason for the difference in forecasts in Fig. 1 is in the historical production data used. From Table 1, we can see that most forecast models are curvefitting models, which means the short-term trend of the forecast curve will be affected by historical production data. In China's oil industry, there are no separate statistics for non-conventional oil production. Therefore, the total historical oil production data are usually seen as the historical conventional oil production by most researchers when they forecast Chinese conventional oil production. That is why many conventional oil forecast curves fit the total historical oil production data well in Fig. 1. The study of Wang et al. (2015) is the first study known to us that breaks out the conventional oil production and non-conventional oil production separately, by collecting the nonconventional oil production data from various sources (See Fig. 1). It can be seen from Table 1 that conventional oil production growth rate becomes significantly lower if non- 
conventional oil production is excluded from the total oil production. However, at present, it is unrealistic to exclude those estimates [including, for example, Wang and Feng (2016)] that use the total historical production data since they hold a dominant position, and we still lack highquality conventional oil production data.

\subsubsection{Recommended result}

Basing policy decisions on such a wide range of forecasts as shown in Fig. 1 is of course difficult. In order to reduce uncertainty, and hence make policy-making somewhat easier, in this paper we have chosen to adopt this "recommended result" approach. We fully accept that reality may turn out different from that indicated by the suggested result, but as indicated elsewhere in this paper there are good reasons for rejecting both the very high and very low forecasts, and here (and in the other cases discussed below) we are reasonably confident that policy decisions formulated at least in part on such "recommended results" are likely to be the most sensible.

In this section, we term the average result of all studies we reviewed as our "recommended result" (see the average conventional oil curve in Fig. 1), except for two types of studies: one is using a URR that does not fully consider the economic factor (i.e. URR values higher than $20 \mathrm{Gt}$ in Table 1); the other is using the negatively skewed curvefitting models. According to this "recommended result" for China's conventional oil production, it seems probable that this has peaked in 2014, with a peak production of $170 \mathrm{Mt} /$ year.

\subsection{Non-conventional oil supply}

Now we turn from considering the production of conventional oil, to that of non-conventional oil. Figure 2 and

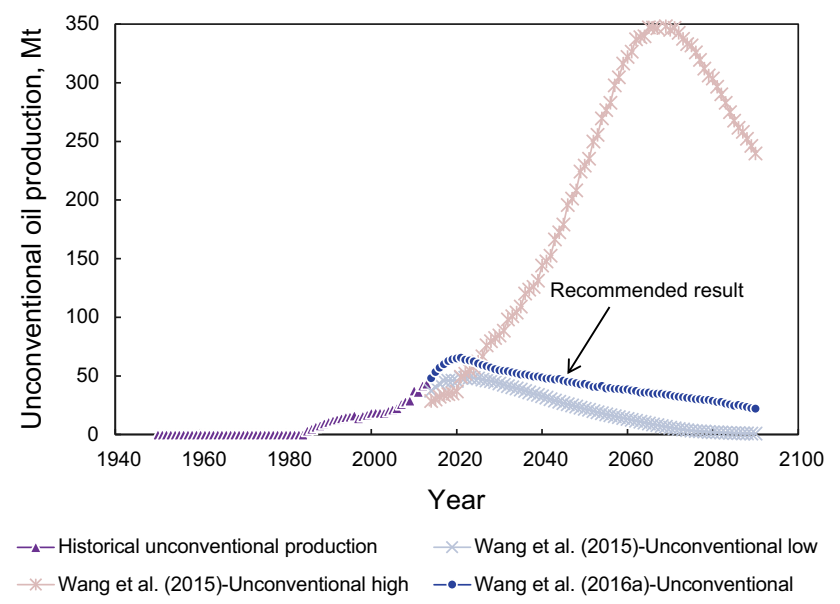

Fig. 2 Production forecasts for China's non-conventional oil resources
Table 2 summarize the results of studies of China's nonconventional oil resources. As can be seen so far, we have found only two such studies. Wang et al. (2015) carried out the first quantitative study of China's long-term non-conventional oil production by using two scenarios. The results under these two scenarios differ significantly. In the high scenario, the total non-conventional oil production will grow considerably in future and reach its peak around 2070, with a peak production of about $350 \mathrm{Mt} / \mathrm{year}$; while in the low scenario, the total non-conventional oil will reach a peak production of about $50 \mathrm{Mt} /$ year much earlier, in 2023 (See Fig. 2). The different URR assumptions are the main reason for this significant difference. As pointed out by Wang et al. (2015), there are no national systematic assessments for URR of each type of China's non-conventional oil resources. Therefore, URR assumptions in both two scenarios are not specific URR estimates. In the high scenario, the technically recoverable resource (TRR), which is $23.4 \mathrm{Gt}$, is used as the URR; while "cumulative production plus reserves", which is only $2.2 \mathrm{Gt}$, is used as the URR in the low scenario. Based on these assumptions, Wang et al. (2015) suggested that the actual production will almost certainly be much lower than production shown in the high scenario but higher than one shown in the low scenario.

Wang et al. (2016a) further developed the study of Wang et al. (2015) by specifically including the economic factor in their analyses. Based on this Wang et al. (2016a), China's total non-conventional oil production is more likely to peak at 2021, at a peak production of close to $65 \mathrm{Mt} / \mathrm{year}$. Wang et al. (2016a) thus also indicate that the actual production of non-conventional oil resources in China is likely to be much lower than the results shown in the high scenario, and higher than the low scenario, of Wang et al. (2015).

In this paper, the median projection, i.e. the forecast of Wang et al. (2016a), is taken as the "recommended result" for non-conventional oil.

\subsection{Total oil supply and its implications for China's oil use}

Based on the above discussion for conventional and nonconventional oil, we can generate a forecast for the likely total oil production in China by combining the above "recommended results" of conventional oil and non-conventional oil. From Fig. 3, we can see that China's total oil production will likely reach its peak around 2018, with a peak production of about $230 \mathrm{Mt} /$ year.

We can then compare this projected total oil production with the forecast for total oil production given in the New Policies Scenario of International Energy Agency (2014). The IEA shows a similar oil production trend. Furthermore, 
Table 2 Summary of the results of studies for projecting China's non-conventional oil resources

\begin{tabular}{lllll}
\hline Researchers & Methodology & URR, Gt & Forecast results & \\
\cline { 5 - 5 } & & & Peak production, Mt & Peak year \\
\hline Wang et al. (2015) & GeRS-DeMo model & $2.2-23.43$ & $48.7-351.08$ & $2023-2068$ \\
Wang et al. (2016a) & SRCGM model & 4.9 & 65.49 & 2021 \\
Recommended result in this paper* & About 5 & About 65 & About 2021
\end{tabular}

GeRS-DeMo model Geologic resources supply-demand model, SRCGM Stochastic resource-constrained growth model

* is the value from Wang et al. (2016a)

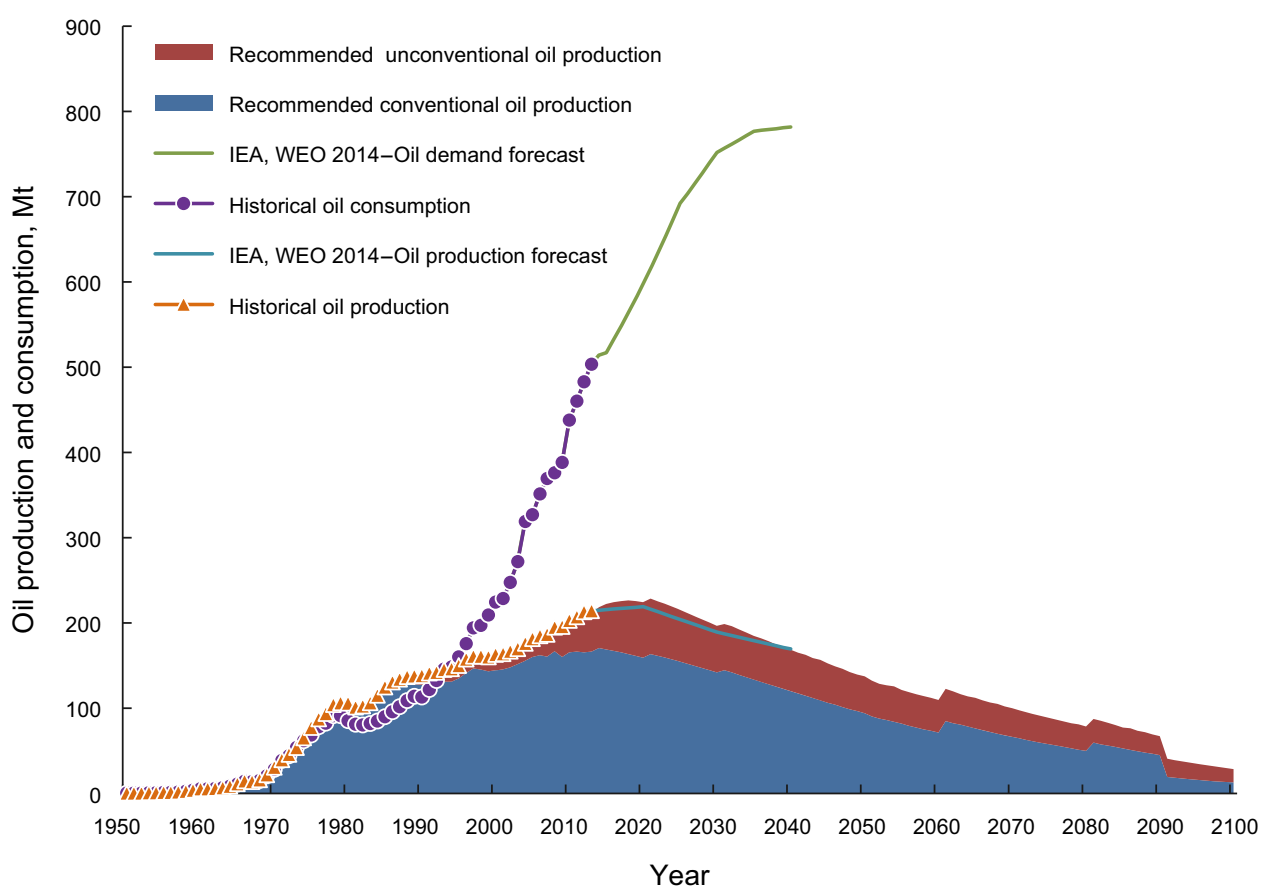

Fig. 3 Comparison of China's domestic oil supply and forecast oil demand

Fig. 3 also indicates the dramatic outcome that results if one compares this paper's suggested oil production with the historical data, and the IEA's forecast oil demand. It can be seen from the figure that China's future oil demand may peak around 2040, with a peak demand of about $780 \mathrm{Mt} /$ year, but before that the oil demand will keep its sharply increasing trend. However, China's total oil production as indicated in this paper is only likely to be about $170 \mathrm{Mt}$ in 2040. This means that China is expected to see the imbalance between demand and domestic production increasing from $308 \mathrm{Mt} /$ year in 2014 to $610 \mathrm{Mt} /$ year in 2040 , with an average annual growth rate of this imbalance of $2.7 \%$. Based on this analysis, oil supply security will remain a serious concern for China. Unless demand for oil falls dramatically, there is no other way to meet this supply gap except by oil imports. In such case, it can be expected that the international oil market will be affected significantly by China's oil import trend.

\section{Gas production}

Now we turn to the production of gas. In the history of China's petroleum industry, the importance of oil was usually higher than that of gas because gas consumption in China was much lower and increased slowly due in part to the lack of infrastructure. However, in 2004 the construction of the first West-East gas pipeline was completed, which has greatly promoted the growth of natural gas consumption. After that, China's gas consumption began to increase rapidly, with an average annual growth rate of 16.4\% between 2004 and 2014 (BP 2015). To meet this soaring gas demand, China's gas production also experienced a rapid growth during the same period, with an average annual growth rate of $12.2 \%$ (BP 2015). However, China's domestic production still did not fully meet its demand, and in 2007, China for the first time became a net gas importer. Thereafter, many studies began to pay 
attention to the long-term production potential of China's gas resources. Similar to the studies of oil production, most studies of gas production are for conventional gas resources; only one study focuses on non-conventional gas resources. Detailed analysis of this topic is given in the following sections.

\subsection{Conventional gas production}

\subsubsection{Overall results}

Figure 4 and Table 3 present the results of a range of studies of China's conventional gas production. Most of these studies were conducted after 2007, for reasons explained in the previous paragraph. As shown in Fig. 4, the differences among these forecasts are significant. According to the studies (see Table 3), the peak year of China's conventional gas production could be between around 2018 and 2049, and the peak production between around 100 and 400 billion cubic metres per year (Bcm/ year).

\subsubsection{Reasons for difference}

The main reasons behind these differences are the same as with conventional oil studies, i.e. URR assumptions, applied forecast models, and the historical production data.
As with oil, the URR gas values from China's authorities are often significantly higher than those suggested in other literature. For example, according to the 3rd National Oil and Gas Resource Assessment, the URR of China's conventional gas resources was $22 \mathrm{Tcm}$ (Li et al. 2006), and this number has been used by several studies (see Table 3). However, much of the literature shows that the URR of China's conventional gas is probably lower, in the 6.7-13.3 Tcm range, with an average value of $10.19 \mathrm{Tcm}$ (Wang et al. 2013a). Similar to conventional oil resources, URR estimates of conventional gas resources also lack full consideration of economic factors. In addition, parts of the tight gas resources are also included in conventional gas resources (Wang et al. 2013a, c).

The models used for gas production forecasting are the same as with conventional oil production modelling, and their impacts on results can be found in Sect. 2.1.

For the historical gas production data, similar to that of the oil production data, there are no separate statistics for non-conventional gas from China's authorities (Wang et al. 2016c). Current studies therefore usually use total gas production as the conventional gas production. Wang et al. (2016c) first presented a comprehensive investigation of historical production gas data from various sources, and then, for the first time, the conventional gas production data were obtained by excluding the non-conventional gas production from the total production data. As can be seen in Fig. 4, most of the forecast production curve fits the total

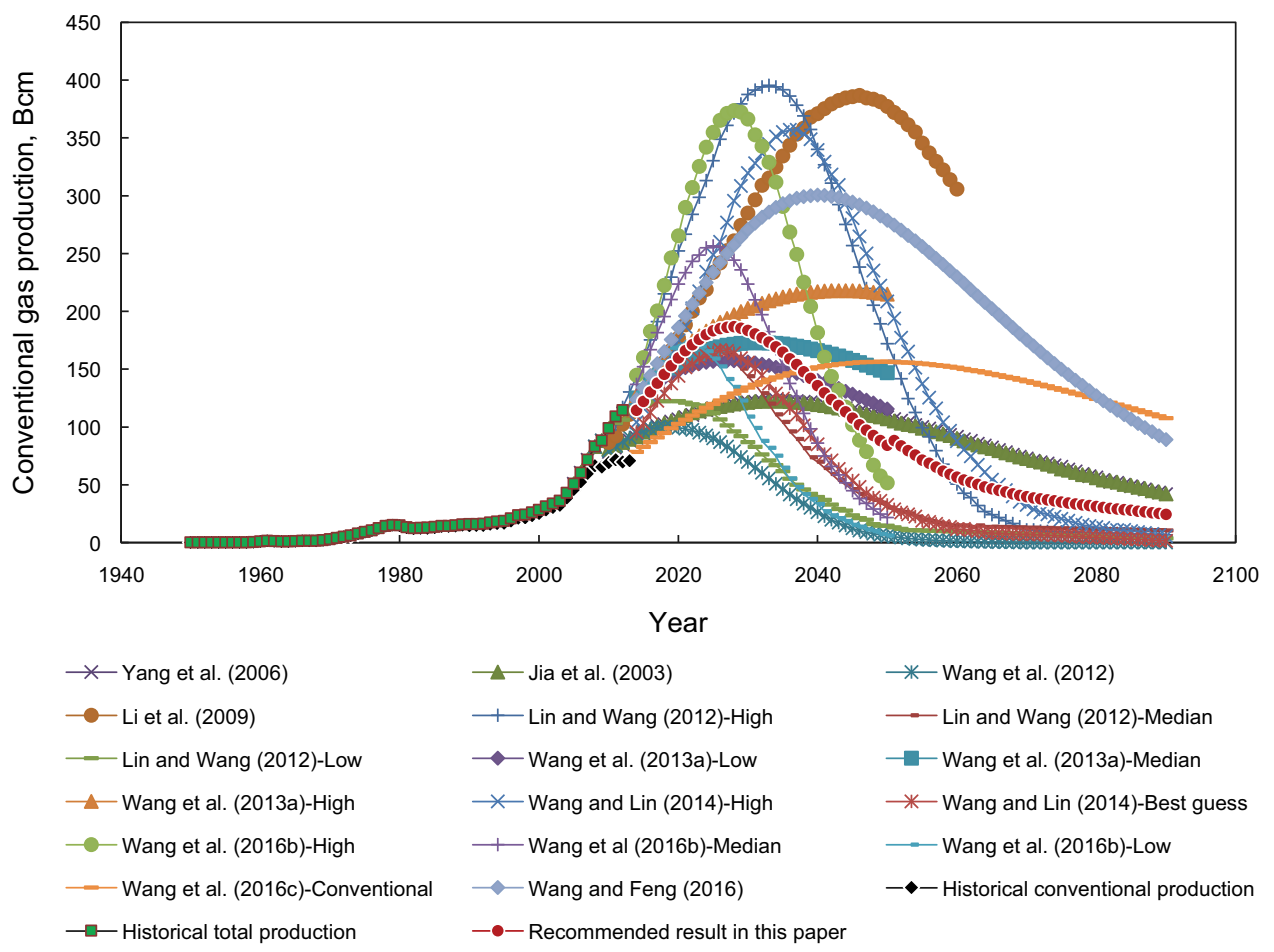

Fig. 4 Production forecasts for China's conventional gas resources 
Table 3 Summary of production forecast for China's conventional gas resources

\begin{tabular}{|c|c|c|c|c|}
\hline \multirow[t]{2}{*}{ Researchers } & \multirow[t]{2}{*}{ Methodology } & \multirow[t]{2}{*}{ URR, Tcm } & \multicolumn{2}{|l|}{ Forecast results } \\
\hline & & & Peak production, $\mathrm{Bcm} /$ year & Peak year \\
\hline Hu (1999) & Gen. Weng model & - & $104-142$ & \\
\hline Wan (2000) & - & - & 100 & 2020 \\
\hline Jia et al. (2003) & - & $10-14.7$ & 120 & 2035 \\
\hline Mou (2004) & - & - & 150 & 2020 \\
\hline Pang et al. (2005) & - & - & 110 & 2026 \\
\hline Yang et al. (2006) & - & - & 125 & 2034 \\
\hline Pang et al. (2009) & - & & 200 & 2026 \\
\hline Li et al. (2009) & Hubbert, $\mathrm{HCZ}$ and Gen. Weng models & 22 & 387 & 2046 \\
\hline Wang et al. (2012) & Gaussian model & 2.46 & 101 & 2018 \\
\hline Lin and Wang (2012) & Gaussian model & $3.82-12.82$ & $117-393$ & 2019-2033 \\
\hline Wang et al. (2013a) & MCGW model & $10.19-22$ & $157-218$ & $2027-2043$ \\
\hline Wang and Lin (2014) & Logistic model & $5.28-12.82$ & $165-356$ & 2025-2035 \\
\hline Wang et al. (2016b) & Multi-cycle Hubbert model & $4.63-10.19$ & $174-376$ & 2019-2028 \\
\hline Wang et al. (2016c) & MCGW model & 16.75 & 156 & 2049 \\
\hline Wang and Feng (2016) & Multi-cycle Richard's model & 22 & 300 & 2040 \\
\hline Summary & & $2.46-22$ & $100-393$ & 2018-2049 \\
\hline Recommended result in this paper* & & About 10 & About 190 & $\begin{array}{l}\text { About } \\
2030\end{array}$ \\
\hline
\end{tabular}

* The "recommended result" is a best guess, based on the average of all collected data, except Li et al. (2009), high scenario in Wang et al. (2013a) and Wang and Feng (2016)

production data curve well, rather than the conventional gas production curve.

\subsubsection{Recommended result}

In this paper, as with oil, we select the average result of all the studies we investigated as our hypothesis of a best guess "recommended result", except those studies that their URR does not fully consider the economic factors (i.e. URR values higher than $20 \mathrm{Tcm}$ in Table 3). From Fig. 4 and Table 3, this recommended result shows that China's conventional gas production will keep increasing and reach its peak in around 2030, with a peak production of about $190 \mathrm{Bcm} /$ year.

\subsection{Non-conventional gas production}

As indicated in the previous section, it appears that only one study has been conducted so far that makes a comprehensive investigation of historical production data and resources/reserves data for each type of non-conventional gas resources that of Wang et al. (2016c). Based on these data, Wang et al. (2016c) also carried out what we believe was the first quantitative study of China's long-term nonconventional gas production. This used the geologic resources supply-demand model (GeRS-DeMo), which is a widely used model for developing the projections of nonconventional fossil fuel production (Mohr and Evans 2010, 2011; Wang et al. 2015). Wang et al. (2016c) develop three scenarios based on different URR assumptions. These are a high scenario (where TRR is treated as the URR), a low scenario (where "cumulative production plus reserves" is used as the URR), and a median scenario (which uses the average of these high and low URRs). It should be noted that resource availability is the only factor considered in Wang et al. (2016c). The potential constraints from environmental issues are not included. Taking shale gas as an example, extracting shale gas may result in many environmental problems, including methane emissions, water use, water pollution, and induced earthquakes (Howarth and Ingraffea 2011; Entrekin et al. 2011; Frohlich 2012). Among these, water issues may be the most significant constraining factor for China shale's gas development. Hydraulic fracking is usually needed in extracting shale gas resources due to their low permeability, which will consume large amounts of pressurized water. Generally, one shale gas well will use more than 20 thousand cubic metres water, and large-scale development of shale gas will surely have serious impacts on local water resources (Jiang et al. 2014; Hu et al. 2013a, b). However, China itself is facing serious water shortage issues (Zhu et al. 2001), which means that local water availability will 
be an important constraint for shale gas development. In a report released by the World Resources Institute, China is labelled as "high" average exposure to water stress over its shale gas and shale oil area (Reig et al. 2014). Therefore, if other constrained factors are considered, the forecast results of Wang et al. (2016c) should be seen as the upper bound of the future production and that the actual production will very likely be lower than results shown in Wang et al. (2016c).

In the present paper, the median result of Wang et al. (2016c) is used as our "recommended result". Based on this result, we can see that China's non-conventional gas production will likely increase significantly in the future and peak at around 2058, with a peak production of around $270 \mathrm{Bcm} /$ year (see Fig. 5; Table 4).

\subsection{Total gas production and its implications on China's gas use}

Putting the above data together, and according to our "recommended" results, China's total gas production is forecast to keep increasing until reaching its peak around 2040 , with a peak production of $350 \mathrm{Bcm} / \mathrm{year}$, and then declining. China's non-conventional gas will play a key role in its future total gas production growth, and its contribution will surpass that of conventional gas in 2034. The IEA (2014) also forecasts China's total gas production, in this case over the period of 2012-2040. According to the New Policies Scenario of IEA (2014), China's total gas production will keep increasing until 2040, which is similar to our recommended results. However, IEA's forecast shows no indication of production peaking at 2040. A comparison of the total gas production recommended in

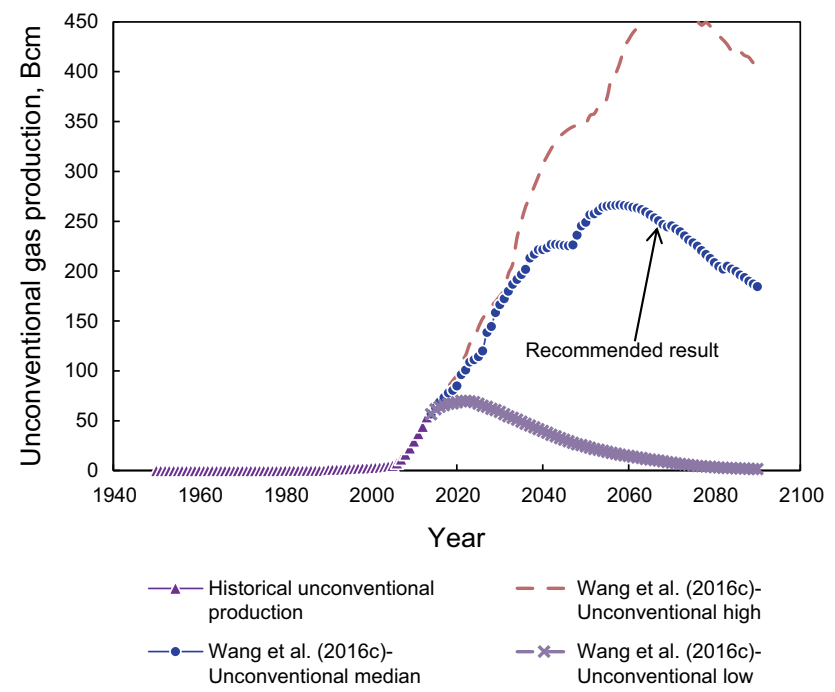

Fig. 5 Production forecasts for China's non-conventional gas resources this paper and the forecast gas demand in the New Policies Scenario of IEA (2014) is presented in Fig. 6. It can be seen from this that China's gas demand is expected to increase rapidly over the next several decades. In 2040, the gas demand will be $600 \mathrm{Bcm} /$ year approximately, while our "recommended result" indicates that China's total gas production will only be $350 \mathrm{Bcm} /$ year by that date, even considering the rapid production increase from non-conventional gas resources. On these predictions, the gap between total domestic gas production and demand will reach $250 \mathrm{Bcm} /$ year in 2040 and is forecast to increase rapidly after 2040 since here the total gas production is forecast to decline after 2040.

\section{Coal production}

\subsection{Overall results}

Coal holds the dominant position in China's energy industry. In 2014, $73 \%$ of total energy supply and $66 \%$ of total energy consumption came from coal (NBSC 2015). For coal resources, the mainstream view in China is that the country is rich in coal resources, so there is no need to worry about a shortage of domestic coal supply. As a result, current studies published between 2007 and 2016 on potential constraints of China's coal production are mainly from international scholars, see Table 5. The corresponding forecasts of China's coal production are displayed in Fig. 7, which shows that the differences among forecasts are still considerable. Based on these estimates, the peak year of China's coal production ranges from 2010 to 2039, and the peak production ranges from $2314 \mathrm{Mt} /$ year to $6096 \mathrm{Mt} /$ year.

\subsection{Reasons for difference}

Many reasons could explain these differences, but we judge the main reason to be the URR assumptions of the different studies.

As indicated above, China's authorities usually report the country as having very large coal resources. However, these resources have little meaning for production unless they can be produced commercially. The portion that can be produced under existing economic and political conditions with existing technology is usually termed as the "reserve", which is much more important for modellers than that of the reported total coal resources, since the former is an important part of URR. However, it is very hard to get accurate estimates of recoverable reserves of China's coal.

The main problem is that the classification system of resources/reserves used by China before 2000 is different 
Table 4 Summaries of production forecast for China's non-conventional gas resources

\begin{tabular}{lllll}
\hline Researchers & Methodology & URR, Tcm & \multicolumn{2}{l}{ Forecast results } \\
\cline { 3 - 5 } & & & Peak production, Bcm & Peak year \\
\hline Wang et al. (2016c) & GeRS-DeMo model & $2.49-42.44$ & $70-470$ & $2021-2069$ \\
Recommended result in this paper* & About 23 & About 270 & About 2058 \\
\hline
\end{tabular}

* is the value for the median case of Wang et al. (2016c)

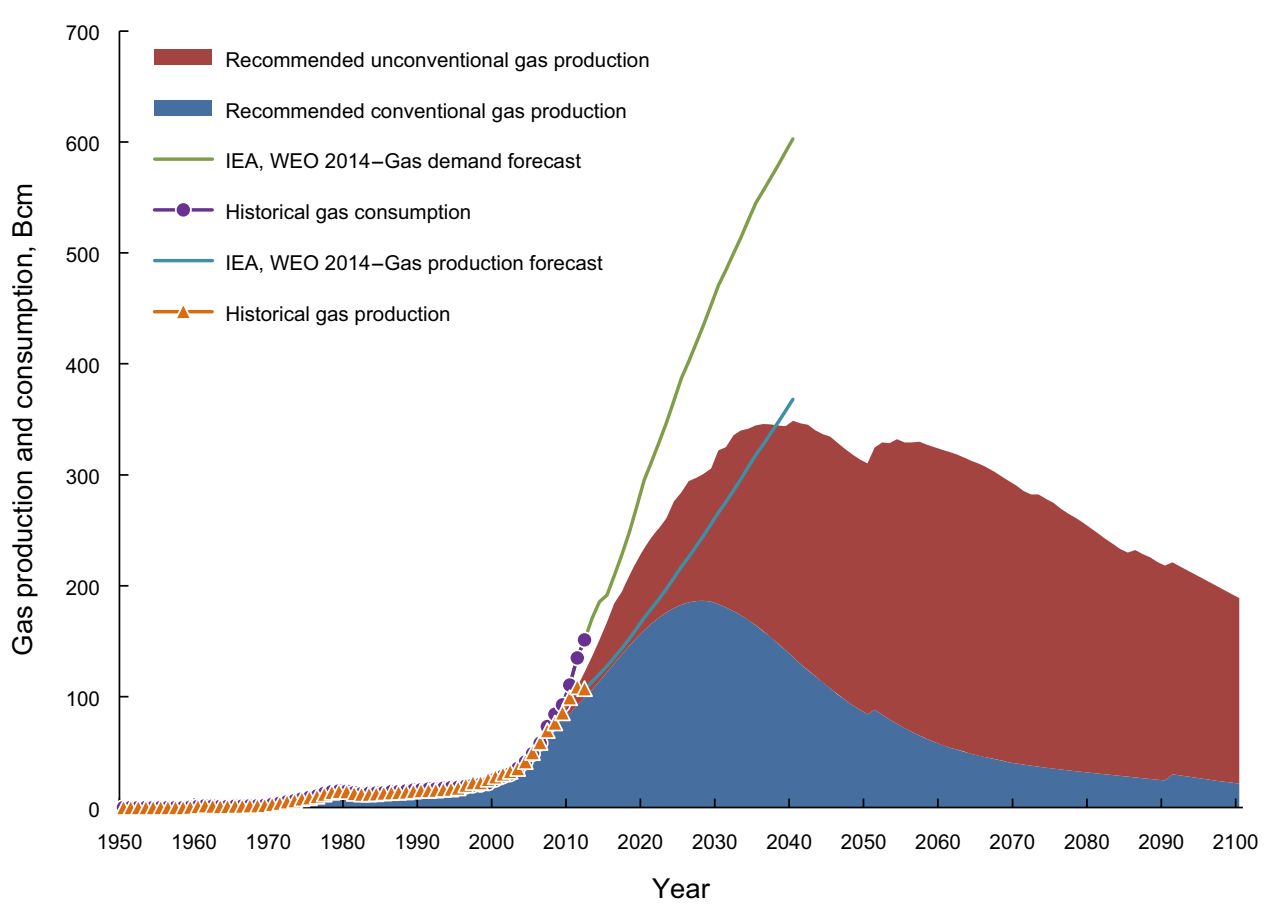

Fig. 6 Comparison of China's domestic gas supply and forecast gas demand

from those applied by international institutes. For example, the term of "coal reserves" was usually used to represent the cumulative discovered coal resources before 2000 (Wang et al. 2013b, c), while in most of other systems, the "reserves" must be discovered, recoverable, and remaining. After 2000, to be in line with the international systems, China released a new classification system. However, those old terms are still widely used and convey the wrong information. For example, Tu (2011) still claimed that China's total coal reserves are $1160 \mathrm{Gt}$ in its report. In addition, some resource/reserve terms in China's new classification system are still difficult to understand. Taking the new term of "basic reserves" as an example, it is very difficult to find a corresponding term from other classification systems (Wang et al. 2013b, c). According to the authorities' explanations, only part of these "basic reserves" can be recoverable because they are in deep, thin or otherwise inaccessible places. In addition to the difference in classification systems, another problem is that the resources/ reserves data reported by different government agencies are different (Wang et al. 2013b, c). Indeed, sometimes the data reported in different reports by the same agency are also different. For example, the discovered resources in 2010 are reported to be $211.5 \mathrm{Gt}$ by the Ministry of Land and Resources of China (MLR) in one report; however, this number is reported to be $57.51 \mathrm{Gt}$ by the MLR in another report. Furthermore, many international reserves statistics from other institutes have reported incorrect data. For example, China's proved coal reserves as reported by both the World Energy Council (WEC) and the BP Statistical Review have remained at $114.5 \mathrm{Gt}$ for years, which itself is an incorrect estimate number (Lin and Liu 2010; Wang et al. 2013b, c). It should be noted in Fig. 7 that early coal forecasts tend to underestimate the potential for coal production to increase, and one key reason is that their URRs are estimated based on WEC and BP's data.

\subsection{Recommended result}

Wang et al. (2013b, c) made a detailed study of China's coal classification system and resources/reserves data. Based on their analyses, China's coal URR is likely to be about 225 Gt. The URR values shown in Table 5 that are higher than $225 \mathrm{Gt}$ are estimates based on the "basic 
Table 5 Summary of production forecasts for China's coal resources

\begin{tabular}{|c|c|c|c|c|}
\hline \multirow[t]{2}{*}{ Researchers } & \multirow[t]{2}{*}{ Methodology } & \multirow[t]{2}{*}{ URR, Gt } & \multicolumn{2}{|l|}{ Forecast results } \\
\hline & & & Peak production, Mt/year & Peak year \\
\hline \multirow[t]{3}{*}{ Tao and Li (2007b) } & \multirow[t]{3}{*}{ SD model } & \multirow[t]{3}{*}{223} & 3339 & 2031 \\
\hline & & & 3784 & 2028 \\
\hline & & & 4228 & 2025 \\
\hline EWG (2007b) & Logistic model & 136 & 2403 & 2015 \\
\hline Li (2008) & Logistic model & 250 & 4245 & 2030 \\
\hline Mohr and Evans (2009) & SDI model & 136 & 2340 & 2010 \\
\hline \multirow[t]{2}{*}{ Höök et al. (2010) } & \multirow[t]{2}{*}{ Logistic model } & 161 & 3383 & 2019 \\
\hline & & 275 & 4834 & 2030 \\
\hline \multirow[t]{2}{*}{ Lin and Liu (2010) } & Logistic model & \multirow[t]{2}{*}{221} & 3830 & 2025 \\
\hline & Gaussian model & & 3665 & 2027 \\
\hline Rutledge (2010) & LPT model & 139 & 2314 & 2019 \\
\hline Patzek and Croft (2010) & Multi-cycle Hubbert model & 147 & 2849 & 2010 \\
\hline Li (2012) & Logistic model & 380 & 6096 & 2039 \\
\hline Wang et al. (2013b) & Modified Hubbert model & 224 & 4119 & 2024 \\
\hline Wang et al. (2013c) & Logistic model & 224 & 3970 & 2027 \\
\hline Wang and Feng (2016) & Multi-cycle Richard's model & 224 & 4404 & 2021 \\
\hline \multirow[t]{3}{*}{ Li (2016) } & \multirow[t]{3}{*}{ Bottom-up multi-Hubbert model } & 350 & 6155 & 2032 \\
\hline & & 285 & 5128 & 2028 \\
\hline & & 220 & 4310 & 2024 \\
\hline \multicolumn{2}{|l|}{ Summary } & $136-380$ & $2314-6096$ & 2010-2039 \\
\hline \multicolumn{2}{|c|}{ Recommended result in this paper* } & About 225 & About 4400 & About 2020 \\
\hline
\end{tabular}

SDI model Supply and demand interactions model, LPT model Logit and probit transforms

* is the maximum of the forecast results, except for results with a URR higher than $225 \mathrm{Gt}$

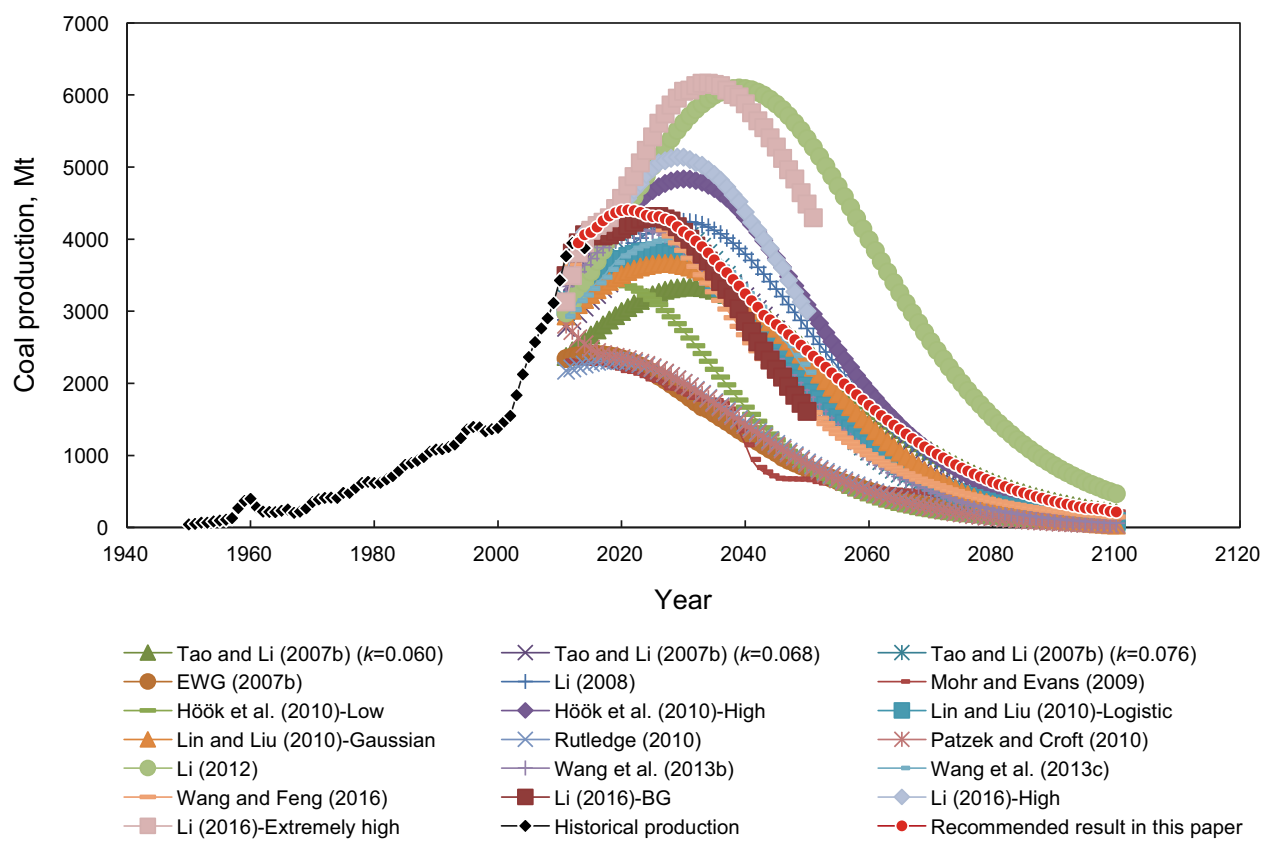

Fig. 7 Production forecasts for China's coal resources 
reserves" or the average value "reserves" and "basic reserves". Therefore, in this paper, our suggested result for China's coal production is estimated to be the upper-bound value of all studies except those studies whose URR is higher than $225 \mathrm{Gt}$ (See Fig. 7).

According to this "recommended result", China's coal production ability could keep increasing until to about 2020 , and the maximum production ability will be about $4400 \mathrm{Mt} / \mathrm{year}$.

\subsection{Implications on China's coal use}

A comparison of China's coal production and its coal demand is shown in Fig. 8. Different from China's oil and gas, coal is the only fossil energy where the Chinese government wants to control its consumption and reduce its proportion in China's primary energy consumption structure.

The three demand curves shown in Fig. 8 reflect three opinions on China's future coal demand trends. Some scholars believe that China's coal demand will keep increasing until China finishes its major transition to full industrialization (Shealy and Dorian 2010; Feng 2012) (see the red line in Fig. 8). Some scholars from climate institutes claimed that China's coal demand must decline immediately to reduce carbon emissions and hence achieve China's promise that carbon emissions will peak no later than 2030 (Green and Stern 2014) (see black line in Fig. 8). Most scholars or institutes think both of the above two opinions are unrealistic, claiming that coal is the only reliable energy source due to its abundant resources. A realistic way they suggest solving the environmental problem is to use coal resources in new ways (such as with clean coal technologies) instead of abandoning the coal resources completely. These experts think that China's coal consumption will keep increasing with a very slow growth rate, or stay at a plateau, until China finishes its full industrialization (NDRC 2009; LBNL 2009) (similar with the green line shown in Fig. 8, or maybe slightly lower).

However, all these above discussions on coal demand do not fully considered the potential supply constraints of China's coal resources. From Fig. 8, we can see that the high demand trend in the Current Policies Scenario is difficult to meet from domestic coal supply. Considering these likely domestic coal supply constraints, a possible pathway for future coal demand is to increase very slowly or stay on a plateau before 2035, and then decline steadily (hence follow a path lower than the coal demand trend shown in the green line in Fig. 8).

\section{EROI analysis for China's fossil fuels}

Studies shown in the previous sections mainly focus on the physical outputs of fossil energy, i.e. emphasizing the final energy outputs without considering the energy inputs in the process of energy exploitation. Net energy or energy

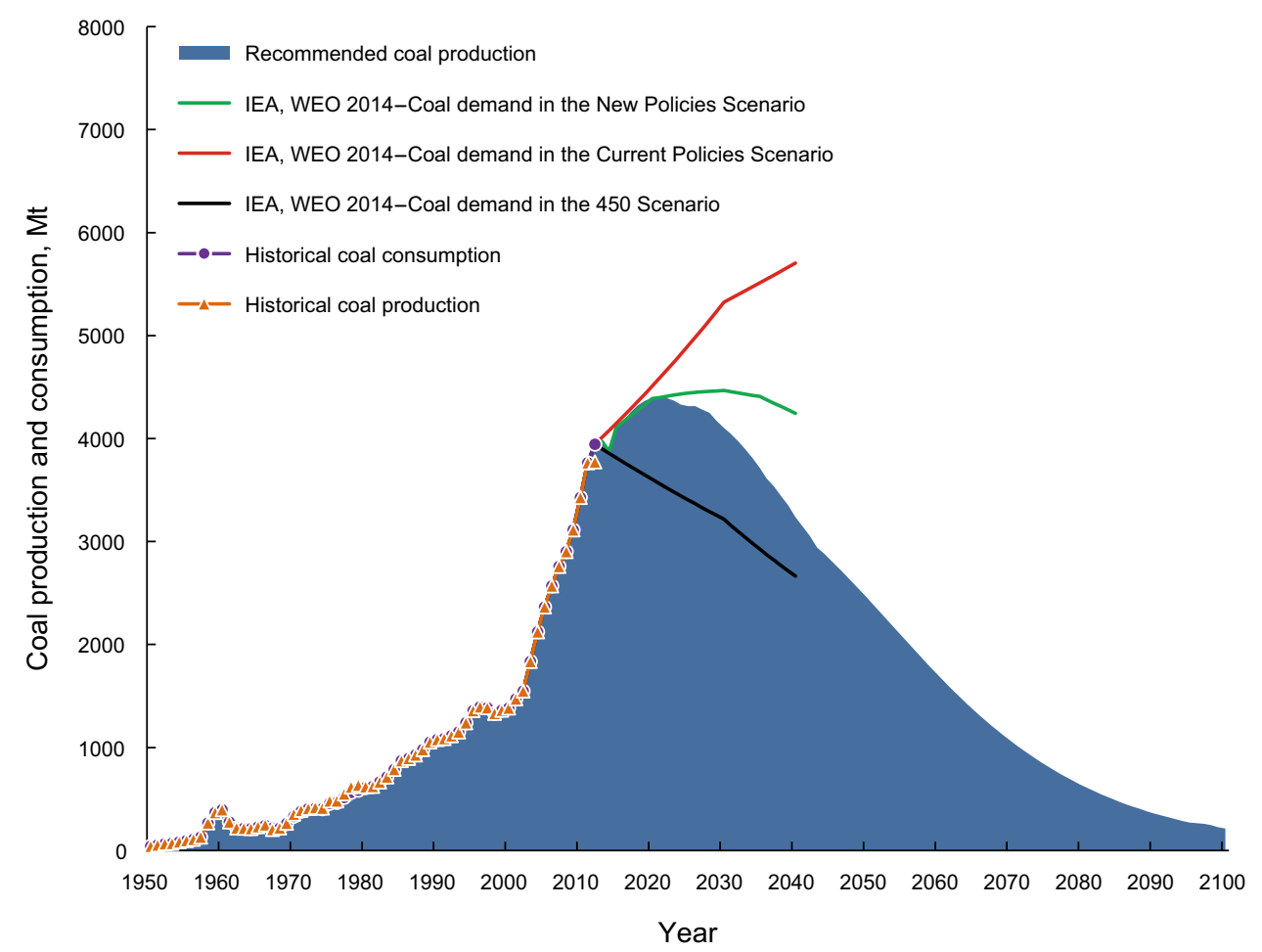

Fig. 8 Comparison of China's domestic coal supply and forecasts of coal demand 
surplus (i.e. energy output minus energy input to get that energy) is the true value of energy resources and is the correct measure of the real energy contribution to society (Lambert et al. 2014). EROI is a suitable tool for net energy analysis, and it can be normally calculated on the basis of thermal equivalence by dividing energy outputs by energy inputs (Hall et al. 1981, 1986; Cleveland et al. 1984).

In the past, fossil fuel resources with high quality (which means very little energy inputs required to extract these resources) were abundant, and their EROI values were usually greater than 30, and up to 100 and over (Guilford et al. 2011). Therefore, there was no great need in the past to be concerned with the fossil fuel net energy outputs or EROIs. However, we have now become aware that the EROI, and hence the amount of energy surplus of fossil fuels to society, has changed relatively recently, due to the rapid depletion of high-quality fossil fuels after about the year 2000 (Wang et al. 2017). Currently, there are an increasing number of studies analysing this issue (for example, Murphy and Hall 2010; Gupta and Hall 2011; Hall et al. 2014). However, there are limited studies on this issue in China. Current studies on EROI of China's fossil fuels are all by $\mathrm{Hu}$ and her colleagues ( $\mathrm{Hu}$ et al. 2011a, b, 2013a, b, 2014a; Xu et al. 2014). The results of these studies are summarized in Fig. 9.

From Fig. 9, we can see that the EROIs of China fossil fuels show a declining trend mainly due to the depletion of shallow-buried coal resources and to the move away from conventional oil and gas resources. The declining trend for coal's EROI is more obvious than those of China's oil and gas, and the specific values of EROI for each fossil fuel are different. As can be seen from Fig. 9, China's coal resources have had the highest EROI in the past, and its EROI value is estimated to be 29.6:1 in 2012 (Hu et al.

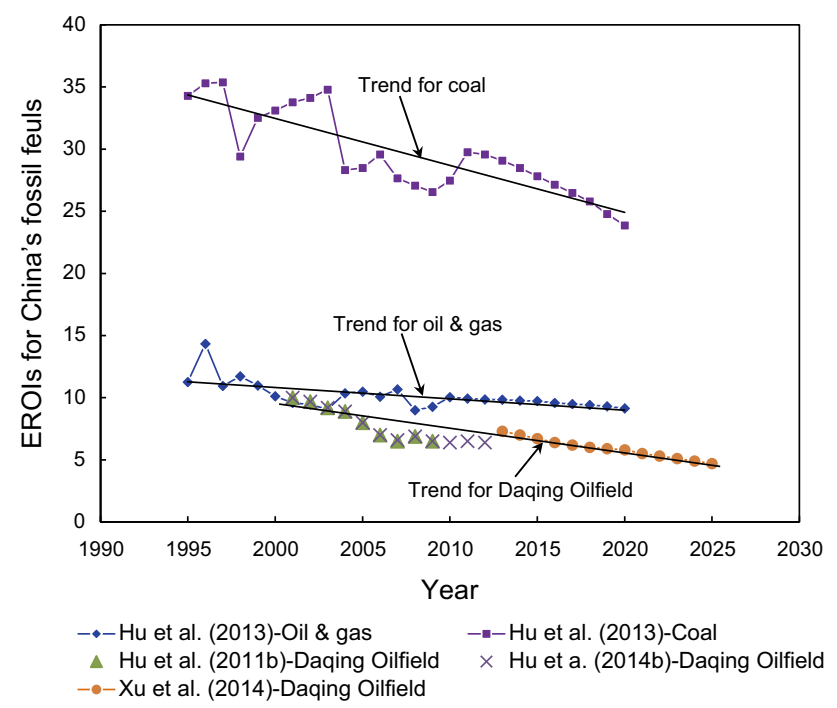

Fig. 9 EROI $_{\text {stnd }}$ for different fossil fuels in China 2013a, b). The EROI of China's overall oil and gas is much lower than that of coal and was forecast to be 9.9 in 2012 (Hu et al. 2013a, b).

It should be noted that the blue line in Fig. 9 represents the total oil and gas industry. There are no separate studies in China for the individual oil and gas industries at a national level because oil and gas are usually concomitant and their input data are also mixed. If the input data for oil and gas can be collected separately, it can be expected that the EROI of oil will be lower than gas since China's oil industry has been developed for years and has entered its mid- and late period, while gas industry is still in its middle and early period. Generally, the inputs during the mid- and later period are much larger. As an example, we can use the case of the Daqing oil field. Daqing oil field, which is the largest oil field in China, has been developed for nearly 60 years and has entered its late period. To maintain its production level or reduce its production decline rate, the Daqing oil field has been using more advanced enhanced oil recovery (EOR) methods for many years, such as polymer flooding and the alkaline-surfactant-polymer (ASP) flooding method (Wang et al. 2016a). All these new methods are well known for their high cost and environmental impact, which in turn leads to lower EROI and declines in the Daqing oil field's EROI. From Fig. 9, we can see that the EROI for Daqing oil field is only 6.4 in 2012 (Hu et al. 2014b), which is the lowest value in our collected data.

\section{Conclusions}

This paper reviews a wide range of studies of China's supply of fossil fuels from two aspects: one is the physical supply, and the other is the net energy supply. Several conclusions can be summarized, as follows:

Firstly, China's conventional oil production appears most probably to have peaked in 2014, with a peak production of $170 \mathrm{Mt} / \mathrm{year}$. Current observed growth in China's total oil production is thus mainly from nonconventional oil resources. A further analysis of future non-conventional oil production shows that the production growth in China's non-conventional oil resources will possibly end as early as 2021; thereafter, its production of this class of oil will also decline. As a result, China's total oil production is forecast to peak in 2018, with a peak production level of $230 \mathrm{Mt} / \mathrm{year}$.

Secondly, China's conventional gas production is forecast to keep increasing and reach its peak during 2025-2030, with a peak production of 180-190 Bcm/year. Non-conventional gas resources are forecast to achieve a rapid development, and we see their production as likely being able to increase until around 2058, reaching a peak 
production at $270 \mathrm{Bcm} / \mathrm{year}$. Due to this great development of non-conventional gas resources, the total gas production in China will keep increasing until reaching a peak at $350 \mathrm{Bcm} /$ year in 2040 .

Thirdly, a reasonable estimate of the upper bound on China's coal production indicates that this is likely to peak at about $4400 \mathrm{Mt} / \mathrm{year}$ by 2020 or so. This finding is likely to be a surprise to most experts from China's coal industry, since the mainstream opinion is that China is rich in coal, and there is no need to worry about supply shortage of its coal resources.

Fourthly, by comparing China's fossil fuel supply and demand, we can see that supply constraints of oil and gas resources are likely to have very serious impacts on China's oil and gas security. The gap between domestic production and demand of oil and gas is forecast to increase rapidly. In addition, coal supply constraints show that that a high coal demand scenario is unlikely to be met from purely domestic production. This is because by considering the supply constraints of China's coal resources, a probable pathway for China's future coal demand appears to be a very slow increase in production, or staying at a plateau, up to 2035 and then to decline steadily thereafter.

Fifthly, three key factors can be used to explain the significant differences among current fossil fuel forecast studies. These are the URR assumptions used, the models applied, and the historical production data used. The problem of the applied models can in principle be solved by technical methods. However, the problems with reliable URR estimates, and historical production data, are usually very hard to solve for a number of reasons, including incomparable classification systems of resources/reserves, and incomplete statistical historical production data (no separate statistics on non-conventional oil and gas resources; and for example different data reported by the same government agency). To better understand the future production of China's fossil fuels, it is crucial for China to improve its data assessment and statistical systems.

Finally, studies of China's fossil fuel supply from the crucial perspective of net energy are summarized here for the first time. A steady declining trend can be observed in the EROI ratios of both the coal and the oil and gas industries due to the depletion of shallow-buried coal resources and of conventional oil and gas resources. This declining EROI trend is generally consistent with the approaching of peaks of physical production of the fossil fuels. The declining EROI ratios in turn mean more and more energy inputs are needed to produce the same amount of energy output. Such a situation will be unsustainable for Chinese society if China cannot find new and abundant energy sources with high EROI values, or find some way to support one and one half billion people at a dignified standard of living by much less energy-intensive means.
Acknowledgements This study has been supported by the National Natural Science Foundation of China (Grant Nos. 71503264, 71373285, 71303258), Humanities and Social Sciences Youth Foundation of the Ministry of Education of China (Grant Nos. 15YJC630121, 13YJC630148), Science Foundation of China University of Petroleum, Beijing (No. 2462014YJRC024) and the Major Program of the National Social Science Found of China (Grant No. 13\&ZD159).

Open Access This article is distributed under the terms of the Creative Commons Attribution 4.0 International License (http://crea tivecommons.org/licenses/by/4.0/), which permits unrestricted use, distribution, and reproduction in any medium, provided you give appropriate credit to the original author(s) and the source, provide a link to the Creative Commons license, and indicate if changes were made.

\section{References}

BP. Statistical review of world energy 2015. London: BP plc; 2015. Brandt AR. Testing Hubbert. Energy Policy. 2007;35(5):3074-88. doi:10.1016/j.enpol.2006.11.004.

Cleveland CJ, Costanza R, Hall CAS, Kauffmann R. Energy and the US economy: a biophysical perspective. Science. 1984;225(4665):890-7.

Chen YQ. Forecast on future oil production and ultimate recoverable reserves in China. Forum Pet Sci Technol. 2003;2:26-31. doi:10. 3969/j.issn.1002-302X.2003.01.005 (in Chinese).

Energy Watch Group (EWG). Crude oil-the supply outlook. 2007a. EWG-SeriesNo. 3/2007. http://www.energywatchgroup.org/ fileadmin/global/pdf/EWG_Oilreport_10-2007.pdf.

Energy Watch Group (EWG). Coal: resources and future production. 2007b. Technical report EWG-Series No 1/2007, Energy Watch Group.

Entrekin S, Evans-White M, Johnson B, et al. Rapid expansion of natural gas development poses a threat to surface waters. Front Ecol Environ. 2011;9:503-11. doi:10.1890/110053.

Feng LY, Tang X, Zhao L. Reasonable planning of oil production in China based on peak oil model. Pet Explor Dev. 2007;34(4):497-501. doi:10.3321/j.issn:1000-0747.2007.04.021 (in Chinese).

Feng LY, Li J, Pang X. China's oil reserve forecast and analysis based on peak oil models. Energy Policy. 2008a;36(11):4149-53. doi:10.1016/j.enpol.2008.07.037.

Feng LY, Li J, Pang X, et al. Peak oil models forecast china's oil supply, demand. Oil Gas J. 2008b;1:43-7.

Feng LY. Analysis on coal import origin of China. Master's thesis for Inner Mongolia University. 2012.

Frohlich C. Two-year survey comparing earthquake activity and injection-well locations in the Barnett Shale. Texas PNAS. 2012;109(35):13934-8. doi:10.1073/pnas.1207728109.

Guo BS, Li HY. Forecast on China's oil production in the initial 21st century. Geol Technol Manag. 1997;5:51-3 (in Chinese).

Gupta AK, Hall CAS. A review of the past and current state of EROI data. Sustainability. 2011;3(10):1796-809. doi:10.3390/ su3101796.

Guilford MC, Hall CAS, O'Connor P, et al. A new long-term assessment of energy return on investment (EROI) for U.S. oil and gas discovery and production. Sustainability. 2011;3(10):1866-87. doi:10.3390/su3101866.

Green F, Stern N. An innovative and sustainable growth plan for China: a critical decade. Policy paper for Grantham Research Institute on climate change and the environment. 2014. http:// www.lse.ac.uk/GranthamInstitute/wp-content/uploads/2014/05/ 
An-Innovative-and-Sustainable-Growth-Path-for-China-A-Criti cal-Decade1.pdf.

Hallock JR, John L, Wei W, et al. Forecasting the limits to the availability and diversity of global conventional oil supply: validation. Energy. 2014;64:130-53. doi:10.1016/j.energy.2013. 10.075 .

Hall CAS, Cleveland CJ, Berger M. Energy return on investment for United States petroleum, coal, and uranium. In: Mitsch W, editor. Energy and ecological modeling. Amsterdam: Elsevier; 1981. p. 715-24.

Hall CAS, Kaufmann R, Cleveland CJ. Energy and resource quality: the ecology of the economic process. New York: Wiley; 1986.

Hall CAS, Lambert JG, Balogh SB. EROI of different fuels and the implications for society. Energy Policy. 2014;64:141-52. doi:10. 1016/j.enpol.2013.05.049.

$\mathrm{Hu}$ CY. Initial discussion on China's gas recoverable reserves and peak production forecast. Mar Orig Pet Geol. 1999;4(3):1-5 (in Chinese).

Höök M, Zittel W, Schindler J, et al. Global coal production outlooks based on a logistic model. Fuel. 2010;89:3546-58. doi:10.1016/j. fuel.2010.06.013.

Hu Y, Feng LY, Tian D. A new method for evaluation of energy production-energy return on energy investment. Energy of China. 2011a;33(01):22-6. doi:10.3969/j.issn.1003-2355.2011. 01.004 (in Chinese).

Hu Y, Feng LY, Hall CAS, et al. Analysis of the energy return on investment (EROI) of the huge Daqing oil field in China. Sustainability. 2011b;3(12):2323-38. doi:10.3390/su3122323.

Hu Y, Hall CAS, Wang JL, et al. Energy return on investment (EROI) of China's conventional fossil fuels: historical and future trends. Energy. 2013a;54:352-64. doi:10.1016/j.energy.2013.01.067.

$\mathrm{Hu} \mathrm{WH}, \mathrm{Hu}$ YH, Yang YW. Analysis of the impacts of shale gas development on water resources, water engineering and water environment in Fuling area. In: Proceedings of the seminar of "Reasonable configuration and efficient utilization of water resources, serving the urban and rural development" organized by Chongqing Hydraulic Engineering Society; 2013b. 1 Aug 2013. (in Chinese).

$\mathrm{Hu}$ Y, Feng LY, Qi C, et al. The impact of energy return on investment (EROI) on economic growth in China. Technoecon Manag Res. 2014a;2:83-7. doi:10.3969/j.issn.1004-292X.2014. 02.016 (in Chinese).

Hu Y, Feng LY, Qi C, et al. EROI and its application in China-Daqing oil field. China Min Mag. 2014b;9:30-4. doi:10.3969/j.issn. 1004-4051.2014.09.009 (in Chinese).

Howarth RW, Ingraffea A. Natural gas: should fracking stop? Nature. 2011;477:271-5. doi:10.1038/477271a.

International Energy Agency (IEA). World Energy Outlook (WEO). Paris: IEA; 2014.

Jia WR, Xu Q, Wang YL. Developing strategy of oil and gas industry under the aim of double GDP in 2020. Energy China. 2003;25(7):18-24. doi:10.3969/j.issn.1003-2355.2003.07.005 (in Chinese).

Jiang M, Hendrickson CT, VanBriesen JM. Life cycle water consumption and wastewater generation impacts of a Marcellus shale gas well. Environ Sci Technol. 2014;48:1911-20. doi:10. 1021/es4047654.

Lawrence Berkeley National Laboratory (LBNL). China's coal: demand, constraints, and externalities. Berkeley: LBNL; 2009.

Li JM, Liu SZ, Li DX, et al. Natural gas exploration in China: current status and development trends. China Oil Gas. 2006;13(2):14-7 (in Chinese).

Li JC, Dong XC, Gao J. China's natural gas production forecast and analysis based on combination model. Future Dev. 2009;30(7):65-9. doi:10.3969/j.issn.1003-0166.2009.07.016 (in Chinese)
Li MQ. Peak energy and the limits to China's economic growth: prospect of energy supply and economic growth from now to 2050. Political Economy Research Institute working paper; 2008.

Li MQ. Peak energy, climate change, and limits to China's economic growth. Chin Econ. 2012;45(1):74-92. doi:10.2753/CES10971475450104.

Li SQ. The study of future supply of China's coal resources and its impacts. Master's thesis for China University of Petroleum, Beijing. June 2016 (in Chinese).

Lin BQ, Liu JH. Estimating coal production peak and trends of coal imports in China. Energy Policy. 2010;38(1):512-9. doi:10. 1016/j.enpol.2009.09.042.

Lin BQ, Wang T. Forecasting natural gas supply in China: production peak and import trends. Energy Policy. 2012;49(1):225-33. doi:10.1016/j.enpol.2012.05.074.

Lambert JG, Hall CAS, Balogh S, et al. Energy, EROI and quality of life. Energy Policy. 2014;64:153-67. doi:10.1016/j.enpol.2013. 07.001 .

Mou SL. The oil and gas exploration and development strategy form: the perspective of present status and future development of China's oil and gas resources. Pet Petrochem Today. 2004;12(1):7-9. doi:10.3969/j.issn.1009-6809.2004.01.003 (in Chinese).

Mohr SH, Evans GM. Forecasting coal production until 2100. Fuel. 2009;88:2059-67. doi:10.1016/j.fuel.2009.01.032.

Mohr SH, Evans GM. Long term prediction of non-conventional oil production. Energy Policy. 2010;38(1):265-76. doi:10.1016/j. enpol.2009.09.015.

Mohr SH, Evans GM. Long term forecasting of natural gas production. Energy Policy. 2011;39(9):5550-60. doi:10.1016/j. enpol.2011.04.066.

Murphy DJ, Hall CAS. Year in review-EROI or energy return on (energy) invested. Ann N Y Acad Sci. 2010;1185(1):102-18. doi:10.1111/j.1749-6632.2009.05282.x.

National Development and Reform Commission (NDRC). 2050 China energy and $\mathrm{CO}_{2}$ emissions report. Beijing: Science Press; 2009 (in Chinese).

National Bureau of Statistics of China (NBSC). China statistical yearbook 2015. Beijing: China Statistics Press; 2015 (in Chinese).

Pang XQ, Meng QY, Bai GP, et al. The challenge and countermeasures brought by the shortage of oil and gas in China. Presentation at ASPO-4, Lisbon Portugal; 2005.

Pang XQ, Zhao L, Feng LY, et al. The evolution and present status of the study on peak oil in China. Pet Sci. 2009;6(2):217-24. doi:10.1007/s12182-009-0035-7.

Patzek TW, Croft GD. A global coal production forecast with multiHubbert cycle analysis. Energy. 2010;35:310-22. doi:10.1016/j. energy.2010.02.009.

Rutledge D. Estimating long-term world coal production with logit and probit transforms. Int J Coal Geol. 2010;85:23-33. doi:10. 1016/j.coal.2010.10.012.

Reig P, Luo TY, Proctor JN. Global shale gas development: water availability and business risks. Washington, D. C.: World Resources Institute; 2014.

Shen PP, Zhao WZ, Dou LR. Oil resource prospects and reserve forecast in China in next decade. Acta Pet Sinica. 2000;21(4):1-6. doi:10.3321/j.issn:0253-2697.2000.04.001 (in Chinese).

Shealy M, Dorian JP. Growing Chinese coal use: dramatic resource and environmental implications. Energy Policy. 2010;38(5):2116-22. doi:10.1016/j.enpol.2009.06.051.

Tao Z, Li M. System dynamics model of Hubbert peak for China's oil. Energy Policy. 2007a;35(4):2281-6. doi:10.1016/j.enpol. 2009.06.051. 
Tao Z, Li M. What is the limit of Chinese coal supplies-a STELLA model of Hubbert Peak. Energy Policy. 2007b;35(6):3145-54. doi:10.1016/j.enpol.2006.11.011.

Tang X, Zhang BS, Deng HM, et al. Forecast and analysis of oil production in China based on system dynamics. Syst Eng Theory Pract. 2010;30(2):207-12. doi:10.12011/1000-6788(2010)2-207 (in Chinese).

Tu JJ. Industrial organization of the Chinese coal industry. Working paper \#103; July 2011. http://carnegieendowment.org/files/ China_Coal_Value_Chain_Kevin_Tu3.pdf.

U.S. Geological Survey (USGS). World Petroleum Assessment 2000. U.S. Geological Survey Digital Data Series-DDS-60; 2000. http://pubs.usgs.gov/dds/dds-060/.

Wan JY. The long and middle term oil and gas multi-development strategy in China. Resources Industries. 2000;Z1(3-4):38-41. doi:10.13776/j.cnki.resourcesindustries.2000.z1.012

(in Chinese).

Wang T, Sun CW, Li XM. China's natural gas production forecast and its price reform. J Financ Res. 2012;3:43-56 (in Chinese).

Wang JL, Feng LY, Lin Z, et al. A comparison of two typical multicyclic models used to forecast the world's conventional oil production. Energy Policy. 2011;39(12):7616-21. doi:10.1016/j. enpol.2011.07.043.

Wang JL, Feng LY, Zhao L, et al. China's natural gas: resources, production and its impacts. Energy Policy. 2013a;55:690-8. doi:10.1016/j.enpol.2012.12.034.

Wang JL, Feng L, Davidsson S, et al. Chinese coal supply and future production outlooks. Energy. 2013b;60(7):204-14. doi:10.1016/ j.energy.2013.07.031.

Wang JL, Feng L, Tverberg GE. An analysis of china's coal supply and its impact on China's future economic growth. Energy Policy. 2013c;57(2):542-51. doi:10.1016/j.enpol.2013.02.034.

Wang T, Lin B. Impacts of non-conventional gas development on China's natural gas production and import. Renew Sustain Energy Rev. 2014;39(39):546-54. doi:10.1016/j.rser.2014.07. 103.

Wang JL, Feng LY, Mohr S, et al. China's non-conventional oil: a review of its resources and outlook for long-term production. Energy. 2015;82:31-42. doi:10.1016/j.energy.2014.12.042.

Wang K, Feng LY, Wang JL, et al. An oil production forecast for China considering economic limits. Energy. 2016a;113:586-96. doi:10.1016/j.energy.2016.07.051.
Wang J, Jiang H, Zhou Q, et al. China's natural gas production and consumption analysis based on the multicycle Hubbert model and rolling grey model. Renew Sustain Energy Rev. 2016b;53(1):1149-67. doi:10.1016/j.rser.2015.09.067.

Wang JL, Mohr S, Feng LY, et al. Analysis of resource potential for China's non-conventional gas and forecast for its long-term production growth. Energy Policy. 2016c;88:389-401. doi:10. 1016/j.enpol.2015.10.042.

Wang JL, Feng LY, Tang X, et al. The implications of fossil fuel supply constraints on climate change projections: a supply-side analysis. Futures. 2017;86:58-72. doi:10.1016/j.futures.2016.04. 007.

Wang JL, Feng LY. Curve-fitting models for fossil fuel production forecasting: key influence factors. $J$ Nat Gas Sci Eng. 2016;32:138-49. doi:10.1016/j.jngse.2016.04.013.

$\mathrm{Xu} \mathrm{B}$, Feng LY, Wei WX, et al. A preliminary forecast of the production status of China's Daqing oil field from the perspective of EROI. Sustainability. 2014;6(11):8262-82. doi:10.3390/ su6118262.

Yu QT. Forecast on oil production and recoverable reserves in China and USA. Xinjiang Pet Geol. 2002;23(3):224-8. doi:10.3969/j. issn.1001-3873.2002.03.014 (in Chinese).

Yang XY, Luo H, Jia WR. Thinking on China's utilization of international oil resources. Energy China. 2006;28(1):6-10. doi:10.3969/j.issn.1003-2355.2006.01.002 (in Chinese).

Yuan C, Liu S, Fang Z, et al. Comparison of China's primary energy consumption forecasting by using ARIMA (the autoregressive integrated moving average) model and GM(1,1) model. Energy. 2016;100:384-90. doi:10.1016/j.energy.2016.02.001.

Zhou ZY. Analysis of China's oil production status and developing potential. China Min. 2003;12(9):4-7. doi:10.3969/j.issn.10044051.2003.09.002 (in Chinese).

Zhang YF, Jia CZ. History contrast and analysis of oil reserves and production increase in China and USA. Research report by Postdoctoral of Research Institute of Petroleum Exploration and Development, PetroChina; 2007. (in Chinese).

Zhu ZY, Zhou HY, Ouyang TP, et al. Water shortage: a serious problem in sustainable development of China. Int J Sustain Dev World Ecol. 2001;8(3):233-7. doi:10.1080/13504500109470080. 